\title{
A desconfiança como elemento de autorreflexividade no cinema de Christian Petzold ${ }^{1}$ Pedro Guimarães \\ Universidade Estadual de Campinas, Campinas, São Paulo, Brasil
}

David Ken Gomes Terao

Universidade Estadual de Campinas, Campinas, São Paulo, Brasil

\section{Resumo}

$\mathrm{O}$ artigo investiga como a representação de um sentimento de desconfiança, como componente da atuação e do agenciamento dos elementos de mise en scène e da recepção fílmica, apresenta-se enquanto um elemento fundamental na obra de Christian Petzold. Por meio da análise fílmica, serão estudados diferentes níveis em que esse elemento de composição fílmica faz-se presente: na construção da visualidade e do ritmo do filme através de sua mise en scène, visando a um claro efeito político na esteira do comentário épico; nas estratégias de jogo atoral autoconsciente, discussão que se filia aos estudos atorais (acting studies) na tradição das relações entre atuação no cinema e o campo teórico do teatro; e um meio pelo qual se cria distanciamento no espectador, espécie de desdobramento das estratégias anteriores. Petzold dá continuidade às propostas estéticas de Douglas Sirk e Rainer Werner Fassbinder, ao utilizar o domínio dos gêneros cinematográficos enquanto um terreno para um cinema político, buscando uma encenação que expõe os processos sociais e históricos que formam a sociedade retratada em seus filmes.

\section{Palavras-Chave}

Teoria e estética do cinema. Gêneros cinematográficos. Estudos atorais.

\section{Introdução}

Importante vertente da discussão sobre a relação entre autoria e autorreflexividade, na esteira dos estudos fílmicos a partir dos anos 1960, pretendeu identificar elementos de comentário textual, com clara visada política e de desconstrução da base dramática clássica, na obra de cineastas identificados como "modernos". Esses realizadores e obras propunham novas camadas de significação dentro do texto fílmico, de modo que os textos comentavam não somente seus meios de representação, como também o posicionamento dos realizadores diante de questões ideológicas despertadas pelas fábulas. O cinema moderno dos anos 1950 não inventou a autorreflexividade fílmica, mas a complexificou, respondendo a um anseio por reinvenção formal do cinema encabeçada por realizadores mundo afora. Objeto exemplar dessa discussão é a obra de Douglas Sirk, embora este seja um realizador associado comumente à estética do cinema clássico. 
Os filmes de Sirk, principalmente a fase de melodramas da Universal (anos 1950), encontra seu caráter autorreflexivo na relação que eles estabelecem com o sistema de produção dos estúdios de Hollywood, do qual eles fazem parte sem se acoplarem inteiramente aos ditames dos códigos pautados pela transparência. A obra de Sirk está na raiz, também, da retomada crítica em torno da obra de outro cineasta autorreflexivo a partir dos anos 1970: Rainer Werner Fassbinder. O panorama crítico em torno da relação desses cineastas começou a ser construído com o interesse das críticas feminista e marxista no melodrama ${ }^{2}$, de modo a traçar discussões de ordem formal e social a partir do cotejamento entre essas obras. Muito já foi falado sobre o uso irônico de motivos plásticos e pictóricos na mise-en-scène sirkiana, bem como das discussões de raça, classe e gênero levantadas por seus filmes. Tão discutida quanto essas observações é a filiação cinematográfica que Fassbinder estabelece com o autor de Hollywood a partir do pastiche de suas formas e da transposição de seus temas para melodramas alemães realizados na década de $1970^{3}$. Propomos acrescentar um prolongamento a essa linhagem de um cinema autoconsciente do ponto de vista formal e, portanto, de claros contornos políticos: a obra de Christian Petzold.

A autorreflexividade na obra de Petzold expressa-se num elemento presente também nas filmografias de Sirk e de Fassbinder: a impossibilidade de relacionamento pleno entre os personagens, que se traduz em corpos em cena que se estranham e expressam uma condição física dúbia de aproximação e afastamento. Tal configuração diz respeito ao posicionamento dos personagens em cena e da maneira de atuar dos atores. Chamá-la-emos "desconfiança" e investigaremos como ela se torna propulsora do questionamento, por parte do espectador, das situações narrativas.

O cinema de Petzold desenvolveu-se na intersecção de um interesse por convenções

1 Artigo proveniente de pesquisas financiadas pela FAPESP (Fundação de Amparo à Pesquisa do Estado de São Paulo) e pela CAPES (Coordenação de Aperfeiçoamento de Pessoal de Nível Superior).

2 Ver WILLIAMS, Linda. Melodrama Revised. In Refiguring American Film Genres. Ed. Nicke Browne. Berkeley: University of California Press, 1998. p. 42-88.VEY, Laura. Notes on Sirk and Melodrama. In GLEDHILL, Christine. Home is where the heart is: studies in melodrama and the woman's film, London: British Film Institute - p. 75-82 e ELSAESSER, Thomas. Tales of sound and fury: Observations on the family melodrama. In LANDY, Marcia (Org.) Imitations of Life: a reader on film and television melodrama. Wayne State University Press, Detroit, Michigan, 1991. p. 68-91

3 Ver as analyses de SMITH, Michael Glover. Sirk/Fassbinder, melodrama mutations. In White City Cinemas. Acesso: https://whitecitycinema.com/2012/03/12/sirkfassbinder-melodrama-mutations/; HAMBURGER, Esther. Sirk, do cinema à TV. In GUIMARAES, Pedro. STARLING, Cássio (orgs.). Douglas Sirk, o Príncipe do Melodrama. São Paulo: CCBB, 2012; e o texto do próprio: FASSBINDER, Rainer Werner. Anarquia da fantasia. Rio de Janeiro: Zahar, 1988. 
narrativas de gêneros cinematográficos e por temas políticos relativos às transformações políticas vividas na Alemanha após a Reunificação, pautada pela implantação de uma economia neoliberal no lugar da divisão entre socialismo e capitalismo. Jaimey Fisher (2013, p. 5) observa que a obra do realizador explora as tendências dos indivíduos de se refazerem diante do contexto socioeconômico, adaptando suas atividades econômicas, seus sonhos e desejos, no que ele chama "refuncionalização econômica". Isso se daria devido às mudanças operadas pelo modelo neoliberal, que causa uma flexibilização do trabalho, o enfraquecimento das solidariedades políticas e a explosão de dívidas financeiras.

Fisher observa que, diferentemente de outros realizadores contemporâneos, como Michael Haneke ou os Irmãos Dardenne, que se distanciam de gêneros populares, Petzold negocia constantemente entre o "cinema de arte"4 e o cinema de gênero (2013, p.11-12). Assim, sem buscar uma reprodução mimética do gênero ou uma negação dele, Petzold realiza "um tipo de arqueologia do gênero, que escava fragmentadamente, recombina e reexibe a serviço de sua própria visão estética e política" (FISHER, 2013, p. 15).
Se os melodramas de Sirk na década de 1950 tratam das transformações da sociedade norte-americana, decorrentes da suburbanização e do questionamento de papéis de gênero e etnia após a Segunda Guerra Mundial, e a obra de Fassbinder acompanha o mal-estar de uma Alemanha dividida e com uma identidade nacional em constante transformação nesse período pós-guerra, o cinema de Petzold vem retrabalhar algumas das questões já abordadas por esses realizadores no contexto de uma agressiva transição para uma economia de austeridade. A desconfiança, herdada desses dois cineastas, faz-se presente na obra de Petzold como uma condição política expressa no trabalho atoral, de modo que a atuação exponha os constantes estados de negociação que caracterizam suas relações.

Tais estados físicos dão-se a ver mediante uma abordagem não naturalista que visa a um distanciamento crítico do espectador em relação à cena. Para melhor compreender essa postura de encenação, é necessário abordar com cautela o chamado Efeito de Distanciamento proposto por Bertolt Brecht, o qual é descrito por ele como um meio de se chegar à "historiação dos acontecimentos", por meio da qual os acontecimentos 
retratados são tornados extraordinários e não mais vistos como naturais, dessa forma sendo possível compreender os processos históricos e políticos por trás deles. Tal distanciamento se constituiria, então, no meio pelo qual o espectador poderia olhar para a realidade política representada nas situações dramáticas (BRECHT, 1978, p. 84-85).

É necessário, antes de qualquer coisa, observar que a estética épica segundo Brecht é muito específica de seu próprio período, na primeira metade do Século xx, e suas supostas transposições para o cinema nunca são completamente fiéis às proposições teatrais desse período. No entanto, por mais que o cinema de Petzold não tenha uma postura de reivindicar a forma épica em sua estrutura narrativa, como é o caso de cineastas como Straub-Huillet ou Godard, pode-se dizer que, através de seus meios próprios de encenação, seus filmes conseguem também distanciar o olhar do espectador, para que ele passe a problematizar, a se inquietar ou, ampliando sua tarefa, a desconfiar da natureza do que lhe é mostrado.

Neste artigo, pretende-se fazer uma análise da desconfiança enquanto elemento de autorreflexividade no cinema de Christian Petzold e, para isso, serão abordados três lugares em que tal elemento faz-se presente. Primeiramente, a desconfiança enquanto elemento temático presente nas narrativas dos filmes do realizador, apresentado como um estado das coisas político que permeia os acontecimentos e demanda uma representação distanciada. Depois, há a investigação a respeito de como a suspeição é exposta no trabalho dos atores (aqui chamados "atores da desconfiança”), pautado em um gestual autoconsciente através do qual se chega ao distanciamento, negando assim a identificação e o naturalismo. Por fim, a análise volta-se para a abordagem política de Petzold no cinema de gênero como meio de inserir o espectador no estranhamento e fazendo com que nele se desenvolva um olhar crítico para as situações que lhe são apresentadas.

Dessa forma, ao resgatar convenções de gênero para comentar um estado das coisas político-social, Petzold aproxima-se da proposta crítica e autorreflexiva do cinema de Sirk, ao mesmo tempo em que se afasta completamente do naturalismo psicológico dominante nos filmes do diretor. Tal como em Fassbinder, o gesto atoral é o lugar do comentário político, que se dá através de um estranhamento criado pelo ator. Tentaremos mostrar como Petzold é um legítimo herdeiro da estética melodramática sirko-fassbinderiana e, ao mesmo tempo, uma terceira via de representação ${ }^{5}$. 


\section{Desconfiança e distanciamento}

Christian Petzold é comumente associado ao que se chama "Escola de Berlim", geração de realizadores alemães do contexto pós-reunificação que partilhavam o desejo por um cinema que caminhasse na direção oposta às grandes tendências do cinema alemão mainstream. Como observam Roger F. Cook, Lutz Koepnick e Brad Prager, tais tendências eram subdivididas entre um cinema de ação, de obras que facilmente agradavam ao público como Corra, Lola, Corra (1988), de Tom Tykwer, e filmes sobre a herança histórica voltada ao passado do país, tendo sua principal expressão em filmes sobre o nazismo como $A$ Queda - As Últimas Horas de Hitler (2004), de Oliver Hirschbiegel. Os filmes de Petzold e seus colegas, por sua vez, buscam a compreensão dos fatos históricos a partir da observação da vida de personagens contemporâneos, cujas vidas encenam, preferindo a objetividade distanciada à representação espetacularizada dos eventos $^{6}$. É importante pontuar, no entanto, que, por mais que esses realizadores tragam algumas questões temáticas em comum, a denominação "Escola de Berlim" como uma maneira de estabelecer uma unidade entre eles é frágil, uma vez que nem todos os realizadores têm formação em Berlim ou realizaram seus filmes lá. Além disso, as abordagens estéticas desses realizadores mostram-se divergentes e polissêmicas, como é o caso de Petzold, que prefere trabalhar em narrativas de gênero em vez do esvaziamento dramático preferido por outros cineastas, como Angela Schanelec.

Nesses filmes, predomina um sentimento de desolação em relação à Alemanha contemporânea. Os personagens, sejam imigrantes, proletários ou burgueses, partilham um não pertencimento em que todos se sentem estrangeiros em um contexto de transições na economia e na política de um país que se reunificou após a queda do Muro de Berlim e passou pela transformação de uma ordem bipolarizada a uma economia neoliberal e individualista. Isso se percebe em diversas nuances dos personagens, no modo como eles se deslocam de um lugar para o outro, na maneira como negociam e, sobretudo, no modo como se relacionam. Ainda que seja

5 Diversos outros cineastas propuseram-se revisitar essa filiação Sirk-Fassbinder: Almodóvar, Haynes, Ozon, Honoré. Acreditamos que o programa estético de Petzold pode ser mais desenvolvido e consistente do que desses outros cineastas, cada, um a seu modo, tendo servido para recuperar a relação entre os dois cineastas e as novas estéticas melodramáticas.

6 COOK, Roger F.; KOPP, K. e PRAGER, B. Introduction: The Berlin School - Under Observation. In COOK, Roger F.; KOEPNICK, L.; KOPP, K. e PRAGER, B. (Eds). Berlin School Glossary. An ABC of the new wave in German Cinema. 1. Ed. Bristol/UK: Intellect, 2013. p. 1-13 
arriscado tentar definir uma obra já robusta (12 longas) em poucas linhas, pode-se dizer que, em Christian Petzold, especialmente pelo trabalho com narrativas de gênero, é possível observar com clareza uma relação de profunda desconfiança entre os personagens. Estes não se perseguem ou fogem uns dos outros como nas formas clássicas do suspense ou do filme policial; tampouco se jogam aos prantos para os braços dos amados, como no melodrama convencional. Antes, eles ensaiam tentativas desesperadas de aproximação, ao mesmo tempo em que se afastam e se retraem. O suspense e o melodrama estão, ainda assim, bem presentes como matrizes semântico-sintáticas nos filmes do cineasta.

Esses corpos que se mantêm nesse estado dúbio de aproximação e afastamento comunicam seus receios a partir de um gestual contido, como se se voltassem para dentro de si mesmos para escapar ao perigo que o contato com o outro pode oferecer. Tal como no duro retrato que Fassbinder traça a partir da Alemanha pós-Segunda Guerra, que se reorganizou em uma ordem bipolar repleta de desconfianças, na Alemanha neoliberal descrita por Petzold, a alteridade é impedida de se desenvolver plenamente pela austeridade que cerca a vida dessas pessoas. Assim, eles também se tornam seres austeros no modo como falam e se movem. O processo de "refuncionalização econômica", referido por Fisher em relação às personagens de Petzold, faz com que as esferas privadas, sejam no âmbito familiar, sejam nas relações amorosas, tornem-se lugares de constante negociação; a hesitação diante das possibilidades de perder tudo nessas transações é exposta nos pequenos gestos do cotidiano. No entanto, se a rigidez dos corpos de Fassbinder era consequência de um trabalho ligado ao teatro de vanguarda do qual o realizador foi participante ativo, em Petzold ela se dá pela rarefação dos conflitos de narrativas de gênero e do esvaziamento das figuras heroicas presentes em tais tramas.

Antes de partirmos para uma análise atoral em algumas obras de Petzold e dos meios pelos quais este agencia um certo distanciamento em relação ao espectador através do trabalho dos atores, interessa aqui observar como a desconfiança enquanto elemento de mise-en-scène concentrado na atuação já estava presente nos cinemas de Sirk e Fassbinder.

No caso de Sirk, um exemplo notório disso é uma sequência de Palavras ao Vento (1956). A secretária Lucy (Lauren Bacall) é levada pelo ricaço Kyle Hadley (Robert Stack) para uma suíte de hotel extremamente requintada onde passará a noite. Visando a impressionar a garota, Hadley demanda uma decoração acintosamente luxuosa: o lugar é repleto de 
arranjos de flores multicoloridas, brilhantes vasos de prata, espelhos em todos os cômodos, perfumes, bolsas, chapéus e roupas caras. Tudo isso é filmado no mais vibrante Technicolor e embalado por acordes de harpas a cada momento de êxtase que a personagem de Bacall (e também o espectador) deveriam experimentar. Lucy, no entanto, não demonstra grande satisfação, tampouco reprovação: seus gestos e seu olhar expressam apenas a mais profunda desconfiança, como se ela se desse conta da artificialidade da situação e dos truques que tentam enganá-la ao fazê-la acreditar em uma suposta felicidade e bonança caso aceite se casar com o milionário mimado e irresponsável (Fig. 1).

Nessa cena, Douglas Sirk constrói um momento emblematicamente autorreflexivo de sua obra. A autorreflexividade faz-se notar quando a forma escolhida pelo realizador permite ir além da primeira camada de significação do conteúdo. O procedimento está presente também na construção dos elementos internos à cena (a decoração do quarto, as cores das paredes, o choque cromático entre dentro e fora do quarto) e na sua relação com os elementos do discurso fílmico: a música que acompanha o percurso da personagem e, principalmente, o jogo atoral de Bacall. A cena serve, assim, de comentário às possibilidades do melodrama em criar situações sublimes de fascínio e epifanias visuais, pautadas pela chave do excesso
Figura 1: 0 quarto luxuriante de Lauren Bacall em Palavras ao vento.
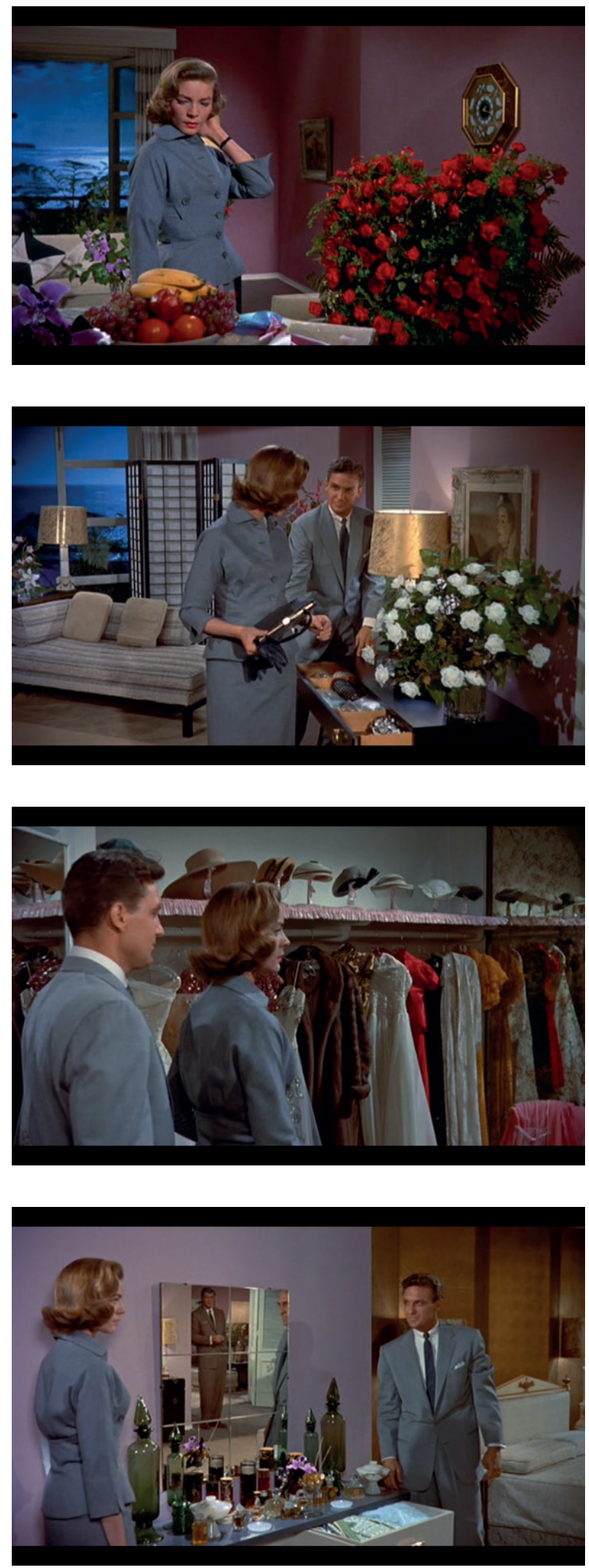

Fonte: Frames do filme 
próprio ao melodrama de estúdio conhecido como "melodrama flamejante" .

Mais importante ainda, o discurso fílmico usa a personagem de Bacall para fazer o espectador questionar-se diante do excesso de beleza e sedução desencadeado por aquela profusão de refinamento e cuidado com a construção do cenário e da imagem. Nessa cena, toda a capacidade de o melodrama clássico mover-nos emocionalmente e de impactar-nos está questionado pela irônica mise-en-scène sirkiana. Lucy materializa, na diegese, o espectador, que se mostra também desconfiado face à explosão visual que a cena propõe.

E é justamente essa maneira de subverter as estruturas do cinema clássico, sem desconstruir totalmente a forma clássica, mas corroendo-a por dentro e aos poucos, que levou Rainer Werner Fassbinder a buscar em Sirk a inspiração para filmar melodramas femininos, a partir dos anos 1970, que questionassem o conteúdo da trama através da organização formal dos planos. No entanto, se na obra de Sirk o que se observa é uma forma ligeiramente autoconsciente dentro do esquema de produção pautado pelas grandes linhas do cinema narrativo-figurativo-emocional ${ }^{8}$, nos melodramas de Fassbinder tem-se um realizador inserido no contexto do Novo Cinema Alemão e influenciado pelas experimentações formais de cineastas como Straub-Huillet. Este é um cineasta que, a certa altura, volta-se para um gênero popular como forma de retrabalhar questões inerentes ao seu universo. Nisso, a pedagogia moralizante que caracteriza o gênero melodrama é transposta para uma estética que foge do esquema naturalista do cinema clássico. Aqui, às narrativas de matriz melodramática e suas diversas convenções de gênero são acrescentadas as experiências do Antiteatro', do qual

7 Jean-Loup Bourget destaca o "melodrama flamejante", geralmente a cores, como uma alternativa, a partir principalmente dos anos 1950, ao "melodrama sério", feito na maioria das vezes em preto e branco e cujo apogeu foram os anos 1930. Tais filmes abusavam da artificialidade na criação de visualidades pautadas por choques cromáticos e paletas de cores berrantes, assim como em situações na quais o excesso da atuação e da expressão do sentimento tornava-se regra. Ver BOURGET, Jean-Loup. Le mélodrame hollywoodien. Paris: Stock, 1985.

8 Para maior compreensão de como Sirk cria distanciamento através da estilização, ver WILLEMEN, Paul. Distanciation and Douglas Sirk, Screen, Volume 12, Issue 2, 1 July 1971, Pages 63-67. Consideramos particularmente pertinente a ideia do uso recorrente pelo cineasta de "imagens-clichês" de maneira a distanciar o espectador, inserindo sua leitura, obrigatoriamente, na história das imagens.

9 Grupo formado em 1968 por Fassbinder e outros integrantes do que foi o "Teatro de ação" de Munique, outro grupo teatral de vanguarda nos anos anteriores. Para uma leitura mais detalhada do trabalho de Fassbinder, ver BARNETT, David. Rainer Werner Fassbinder and the German Theatre. Cambridge, UK; New York, NY: Cambridge University Press, 2005. 
Fassbinder foi fundador e onde se criava um teatro político a partir das ideias de dramaturgos como Bertolt Brecht.

Em Fassbinder, está presente algo do estado de desconfiança de Bacall, de maneira, no entanto, mais latente que aquela apresentada no personagem sirkiano. Na sequência do hotel paradisíaco, tal desconfiança insere uma camada de reflexividade em meio a uma encenação que podemos chamar de naturalista, pautadas por outros códigos e por um contexto, os quais não são, a princípio, reflexivos o bastante para subverter os efeitos de identificação do espectador. Nas de Fassbinder, por sua vez, a reflexividade infiltra-se em diversos elementos formais próprios ao cinema moderno, nos quais o sistema de identificação e compreensão do espectador, através da transparência do dispositivo, é desmontado em favor de um olhar crítico que acompanha cada gesto. A encenação então visa ao distanciamento, abrindo novas perspectivas sobre a visão crítica dos processos históricos que formaram a consciência do povo alemão. Tome-se como exemplo O medo devora a alma (1974), melodrama em que Fassbinder transpõe a trama de Tudo o que o céu permite (1955), de Douglas Sirk, para o contexto da Alemanha pós-Hitler. No filme de Sirk, a jovem e rica viúva Cary (Jane Wyman) apaixona-se por seu jardineiro Ron (Rock Hudson), romance
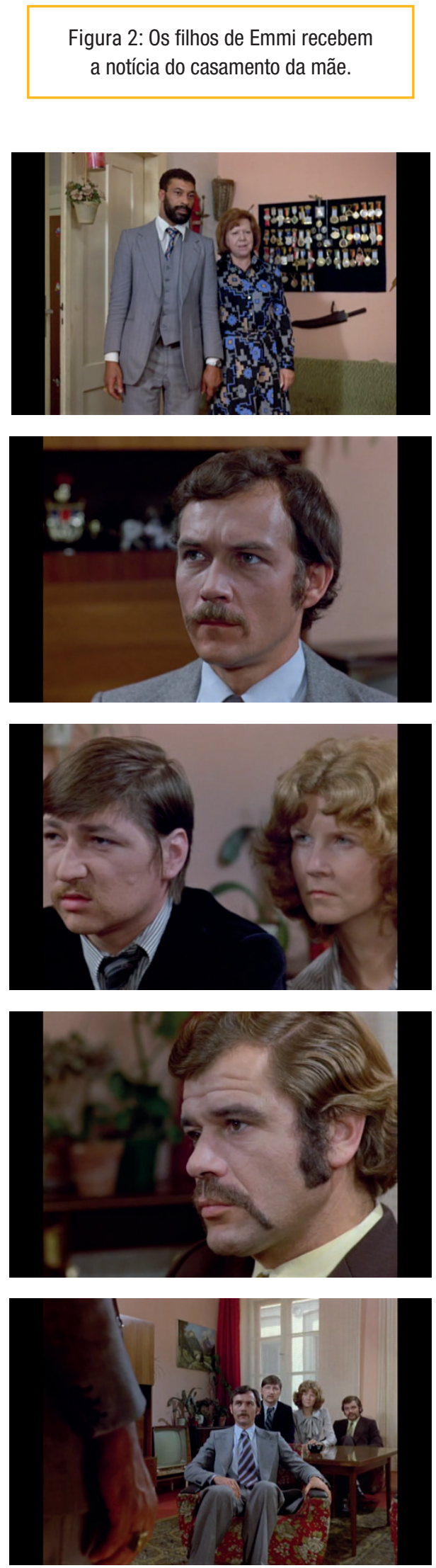

Fonte: frames do filme 0 medo devora a alma 
que inflama a puritana sociedade da qual ela faz parte. Em Fassbinder, a viúva alemã Emmi (Brigitte Mira) é idosa, e o homem por quem se apaixona, Ali (El Hedi ben Salem), além de bem mais jovem, é imigrante árabe. $\mathrm{O}$ aprofundamento dos focos melodramáticos por parte de Fassbinder, assim como o destaque para a inscrição político-social estão bem marcados nessa escolha de tipos de atores distintos entre os dois filmes. No remake, dentre as diversas cenas em que o casal enfrenta o olhar de julgamento da sociedade, há uma em especial que problematiza o jogo da desconfiança por parte dos atores e o preconceito dos personagens. Após casar-se com Ali, Emmi apresenta-o aos filhos. Ao dizer que se casou, chama o marido, que entra na sala fazendo uma rebuscada mesura para a família. O que se segue é a descrição dos olhares, estupefatos, dos filhos e do genro (Fig. 2), por um movimento de câmera lateral; depois, a explosão de raiva de um dos filhos, que destrói a televisão e sai da sala, seguido pelos outros. A filha ainda para no soslaio da porta para destilar um último impropério agressivo à mãe, chamando pelo marido. Emmi, então, chora contidamente no fundo da sala, enquanto Ali a consola ${ }^{10}$.
Essa cena problematiza não apenas o racismo e a xenofobia de uma família alemã, mas também coloca em questão, reflexivamente, o trabalho de atores como vetor de construção de sentido dentro da trama. A atitude de estupefação dos filhos dá-se por um registro de atuação que foge do excesso característico do melodrama, antes se dando por uma apatia inicial a partir de um congelamento dos gestos, que reproduz a configuração dos diversos tableaux que Fassbinder utiliza ao longo do filme, em cenas em que o casal passa pelo olhar julgador da sociedade. Diante da forma artificial e dilatada através da qual a reação violenta deles é apresentada, o espectador indaga a forma fílmica por ter mostrado pessoas passando paradoxalmente da passividade à explosão de raiva desmesurada, contida na quebra da TV e no xingamento de "pocilga", proferido pela filha ao lar materno. A desconfiança inicial dos atores fassbinderianos, que já havia sido expressa no momento em que Emmi entra pela primeira vez no bar onde conhece Ali, todos fitando-a longamente, imóveis, cristaliza-se nesse momento de representação de uma realidade político-social sufocada, mas não menos violenta, através de uma encenação que não esconde seu caráter de comentário ao extrafílmico.

10 A cena traz também uma citação ao momento similar do filme de Sirk pelo viés do objeto televisão, dada em presente à mãe pelos filhos do filme de 1956, e destruída no remake pelo chute nervoso do filho. 0 marido da filha, que posa ao lado do objeto televisão, é vivido pelo próprio Fassbinder. 
Georg Seesslen observa que os filmes dos realizadores da "Escola de Berlim" requerem um tipo de ator que prefere o minimalismo ao excesso, não se fundindo totalmente com o personagem, criando um distanciamento em relação ao espectador. Dessa forma, os realizadores rejeitam a visão psicologizante dos personagens, preocupando-se antes em mostrar os percursos das pessoas em cena. A partir de tal distanciamento, evita-se a catarse que, de alguma forma, poderia redimir os personagens ou dar alguma perspectiva de consolação para o espectador. O resultado é uma entrada na trama através de uma perspectiva mais ampla, política, a qual não responde a todas as perguntas ou alcança o transcendental (2013, p. 12-18). Dessa maneira, a atuação no cinema de Petzold apresenta-se como uma continuidade às propostas estéticas de Sirk e, sobretudo, de Fassbinder, uma vez que nela o objetivo é pensar os discursos por trás das ações dos personagens e trazê-los para o primeiro plano, já que o ator que compõe o personagem não desapareceria totalmente atrás dele.

Gerd Bornheim, ao fazer uma leitura da estética brechtiana, observa que o distanciamento na obra do dramaturgo dá-se em diversos níveis: no nível do espectador, do ator e do diretor, sendo utilizados elementos diversos para se chegar a ele: dos elementos cênicos e cartazes das apresentações à música (1992, p. 248). No entanto, Bornheim chama a atenção para o trabalho atoral enquanto elemento central para se alcançar o "efeito de distanciamento", uma vez que o ator é "o grande intermediário, o elemento vivo de ligação entre o texto e o espectador" (BORNHEIM, 1992, p. 257).

Para que tal efeito seja mobilizado no espectador, Brecht chama a atenção para a necessidade de um método que se oponha ao da metamorfose do ator em personagem, ou seja, da mimesis transparente que caracteriza o drama convencional e que dá à cena o tom de naturalidade e presentificação, como se os acontecimentos e as interações se criassem naquele exato momento. O que Brecht propõe, no entanto, como uma "nova técnica da arte de representar" deve se afastar de qualquer "atmosfera mágica" que hipnotize o espectador. Para seguir um outro caminho, os atores deveriam deixar nítido o ato de mostrar, de expor o caráter de seus gestos em vez de diluí-los em uma representação que se assemelha a uma ordem natural (1978, p. 79-80).

O trabalho atoral não necessariamente renunciaria ao recurso da empatia, mas ela não seria seu principal objetivo e sim a exteriorização de todos os elementos de natureza emocional (1978, p. 80). O ator busca, portanto, mesmo em uma narrativa que dê espaço a uma partilha emocional com o espectador, deixar claro 
na sua composição que se trata de um procedimento autoconsciente de atuação, o qual comunica estados físicos e emocionais do personagem ao público, mas que, ao mesmo tempo, comenta a própria atuação através de estratégias de autorreflexão sobre seu ofício. Por meio do efeito de distanciamento, dever-se-ia expor o "gesto social" ou gestus, o qual Brecht define como "a expressão mímica e conceitual das relações sociais que se verificam entre os homens de uma determinada época" (1978, p. 84).

Em uma definição mais complexa mais adiante, Brecht abordaria o gestus da seguinte maneira:

Com esta palavra compreendemos todo um complexo de gestos isolados dos mais diversos tipos, associados a declarações, que se relacionam às bases de um acontecimento humano que pode ser separado e que se refere à atitude geral de todos relativamente a este acontecimento (como a condenação de uma pessoa por outras, ou uma deliberação, ou uma luta, e assim por diante); ou um complexo de gestos e declarações que, vindos de uma única pessoa, desencadeia certos acontecimentos (a atitude hesitante de Hamlet, ou a confissão de Galileu, e assim outros mais); ou ainda, simplesmente a atitude de base de uma pessoa (como a satisfação ou a espera) (BRECHT, apud BORNHEIM, 1992, p. 283).

Assim, por meio da exposição do gestus seria permitido conhecer os processos sociais por trás dos acontecimentos, uma vez que, como vimos em Brecht, os fatos da narrativa são abordados com o caráter de acontecimentos históricos, desenvolvendo um olhar propositivo ou questionador, em outras palavras, crítico, no espectador. Como bem resume Anatol Rosenfeld (2008), "o tornar estranho, o anular a familiaridade da nossa situação habitual, a ponto de ela ficar estranha a nós mesmo, torna essa situação mais conhecida e mais familiar [...] trata-se de um acúmulo de incompreensibilidade até que surja a compreensão" (ROSENFELD, 2008, p. 152).

\section{$\mathbf{0}$ ator da desconfiança}

Uma vez introduzidas as noções de efeito de distanciamento e gestus a partir de Brecht, pode-se retomar a questão do ator no cinema de Petzold, que aqui é chamado ator da desconfiança. No âmbito da narrativa, é possível observar que os conflitos e as nuances das relações entre os personagens são encenados de modo a levantar sempre as questões políticas que eles carregam, mesmo que isso se dê nas sutilezas de um movimento, de uma relação entre personagens ou de uma expressão facial. Esses conflitos, de ordem privada, relacionamentos familiares, afetivos ou de trabalho, são tomados pela mais profunda desconfiança. Há diversos momentos em que as relações de poder são colocadas em jogo, e os atores expõem no seu gestual a impotência que sentem na tentativa de se comunicarem 
e se envolverem, ao mesmo tempo em que sobrevivem em situações inóspitas.

Pode-se falar, então, que o que o cinema de Petzold revela é um gestus da desconfiança, em que os corpos se repelem e contêm seus gestos ao máximo, como se algo os prendesse e não permitisse aquela expressão livre e equilibrada que se tornou convencional do cinema clássico naturalista. Para melhor compreender como esse conjunto de expressões físicas expõe essa condição vivida pelos personagens, é preciso abordar alguns exemplos em filmes de Petzold.

Wolfsburg (2003) conta a história de Phillip (Benno Fürmann), vendedor de carros que, por acidente, atropela um garoto que andava de bicicleta na estrada e foge sem prestar socorro à criança. Tomado pela culpa, vai até o hospital local e encontra a mãe, Laura (Nina Hoss), trabalhadora de um frigorífico, e tenta estabelecer contato com ela. A cena do primeiro encontro resume como a desconfiança age como ponto de partida das relações entre os personagens. Os corpos rígidos, pela pressão de um relacionamento em crise vivida por Phillip e pela opressão no ambiente de trabalho e pelo temor pela vida do filho acidentado experimentados por Laura, mostram aqui esse estado das coisas. As relações de poder e classe dão-se a ver no momento em que Phillip se aproxima de Laura, que está diante de uma máquina de café. De repente, ela irrompe em choro e, incomodada pela aproximação, olha de rabo de olho para ele e sai de perto. O registro do jogo atoral e o dispositivo tratam de esconder a emoção da personagem: ora ela chora contidamente escondendo o rosto, ora seu rosto é escondido pela estrutura da máquina de café, ora ela sai do quadro. O dado melodramático da expressão excessiva é furtado ao espectador e ao homem que está diante dela. Phillip aproxima-se da máquina, e Laura retorna, reivindicando aquele café como dela. Ele então, em tom conciliatório, pega-o e entrega na mão dela, dando-lhe um cigarro também quando ela o pede. Após acendê-lo, ele tenta iniciar uma conversa, que é interrompida pela voz da enfermeira que grita chamando Laura até o quarto de seu filho, que acabara de acordar. (Fig. 3)

Aqui, tal como Brecht (1978) propunha como resultado do distanciamento, uma situação corriqueira é tornada extraordinária uma vez que, a partir dela, comenta-se a estrutura social em que ela está inserida. Uma ação banal como pegar um café da máquina mostra-se um jogo de posse em que o explorado que perde tudo luta para manter o mínimo que ainda tem. A circulação da morte iminente impede uma tentativa de conciliação entre um agente do mercado e uma proletária. A rigidez dos corpos na culpa e na 
Figura 3: A aproximação em Wolfsburg.
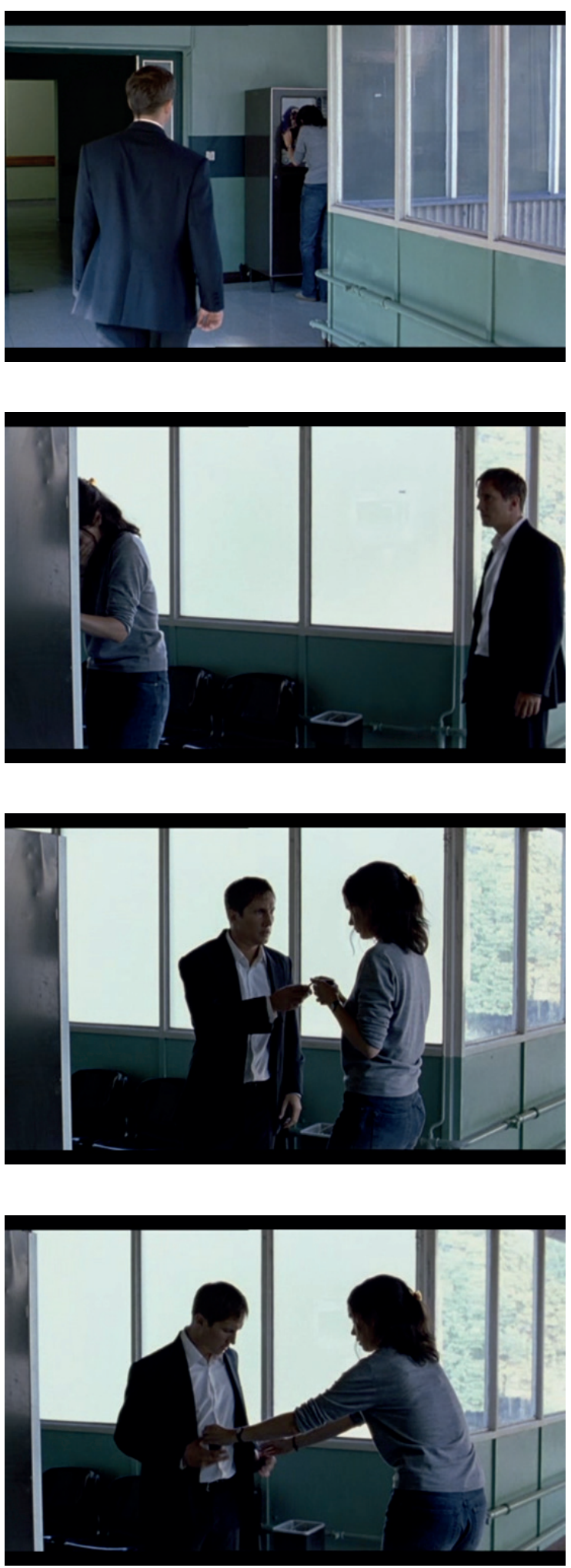

Fonte: Frames do filme desolação, a negação das emoções diante do outro e a atitude defensiva de quem não quer ceder mais expõem o gestus da desconfiança no capitalismo contemporâneo.

Outro exemplo de relação conflitante entre corpos, que nesse caso se desejam, mas se repelem, é Jerichow (2008). O filme retrabalha a clássica trama de O Destino Bate à Sua Porta, romance de 1934 de James M. Cain, adaptado anteriormente para o cinema. Na fábula, um empregado envolve-se com a esposa de seu patrão e arma um complô com ela para assassiná-lo. O empregado aqui é Thomas (Benno Fürmann), militar desempregado que, em meio a uma busca por emprego e um problema com agiotas, cria uma proximidade com Ali (Hilmi Sözer), turco que gerencia uma rede de restaurantes no interior. Nisso, o patrão contrata-o como motorista e, à medida que a relação de trabalho entre os dois se desenvolve, Thomas se vê cada vez mais atraído por Laura (Nina Hoss), a esposa do patrão.

Na sequência da confraternização na praia, ao som de uma música turca, o patrão dança com uma garrafa de bebida, enquanto sua esposa e seu empregado o observam apáticos. Ele coloca os dois para dançarem juntos ironicamente dizendo querer ver "como os alemães dançam" (Fig. 3) e sai caminhando bêbado até sair do campo de visão dos dois. Longe de Ali, Thomas beija Laura em meio à dança. 
Ela corresponde ao beijo por alguns instantes, mas o afasta agressivamente.

A afirmação do poder do patrão e marido faz-se notar ao tentar unir os dois em uma dança, mesmo com o visível desconforto dos dois, reforçado pela transgressão do lugar que ambos ocupam em relação a Ali no breve beijo adúltero. As cenas de desejo quase sempre são interrompidas ao longo do filme, seja pela confiança ainda não estabelecida ou, mais tarde, em uma cena de sexo entre Laura e Thomas, pela necessidade da manutenção das aparências do casamento.

A questão dos imigrantes está pautada no filme a partir do personagem Ali, que, embora tenha um certo poder sobre seus empregados, vê-se na condição de um estrangeiro que luta para fazer parte daquele lugar. Fisher observa que, nessa cena, o turco age como o metteur-en-scène típico do gênero noir, que manipula os outros como fantoches econômica e emocionalmente (2013, p. 130). Por meio da música e da dança, Ali afirma seu poder como o realizador efêmero de um número musical. A partir desse jogo de cena orquestrado por ele, a ordem das coisas obedece aos desejos do marido-patrão, e os alemães passam a ser os estrangeiros que seguem suas indicações, ao mesmo tempo em que desenvolvem um desejo um pelo outro. Aqui há também uma subversão das relações de poder e do
Figura 4: 0 marido "ensaia" a cena da dança em Jerichow.
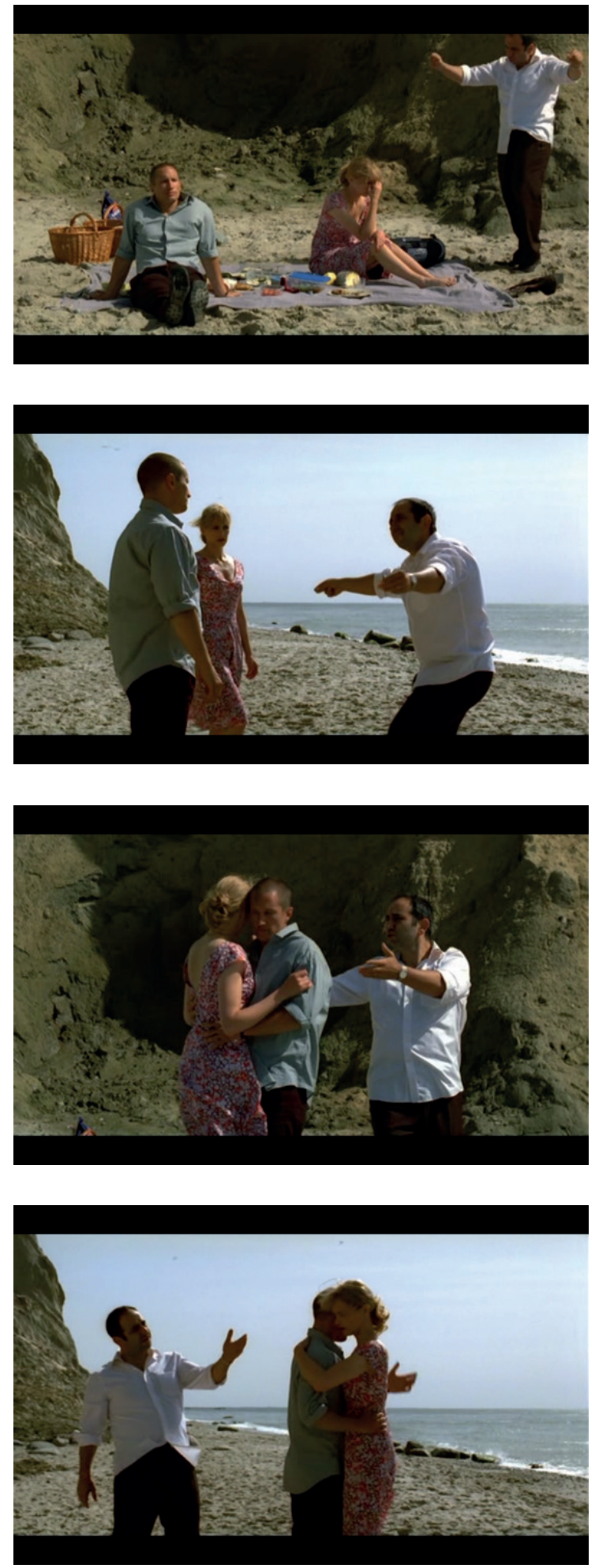

Fonte: Frames do filme 
Figura 5: Toni (à esq.) e Nina (à dir.), posturas distintas em cena do casting de Fantasmas.

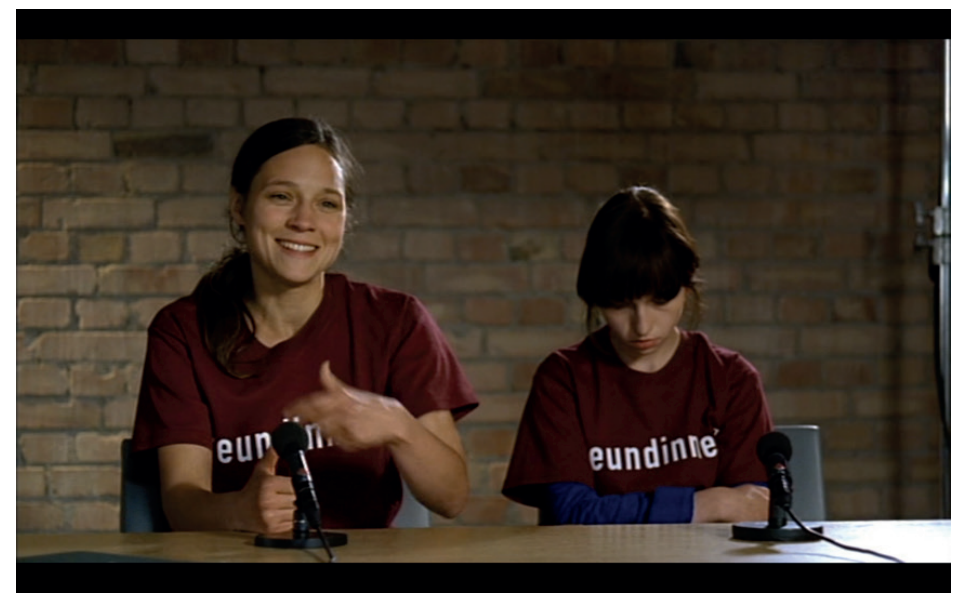

Fonte: Frame do filme

lugar que os personagens envolvidos nelas ocupam na narrativa. Se, em O medo devora a alma, o imigrante (que também se chama Ali) é apresentado enquanto um homem oprimido e marginalizado, em Jerichow ele é o retrato das múltiplas nuances e da possibilidade de transitar entre diferentes posições sociais em uma sociedade de mercado.

Em Fantasmas (2005), Petzold desenvolve uma das cenas que melhor problematiza as relações entre ator e personagem e a construção do drama. Nina (Julia Hummer) é uma garota órfã que se envolve afetivamente com Toni (Sabine Timoteo), jovem delinquente sedutora, com quem passa a deambular por Berlim. Toni, desempregada, chama Nina para tentarem um casting. Lá, elas devem contar uma história sobre como se conheceram diante de um produtor e sua equipe. Toni bola uma história envolvendo um barco em uma tempestade e uma noite dançando no deck do navio após se salvarem, crendo que isso convencerá o produtor. No entanto, no momento da apresentação, ela é tomada pelo nervosismo, e sua narrativa não convence o produtor e a equipe, que caem rapidamente no tédio diante do relato. Antes de desistir totalmente daquelas candidatas, o produtor pergunta, num ultimato, como elas se conheceram de verdade. Toni então pede angustiada para que Nina a ajude. A garota, que até então não tinha falado nada, começa a relatar pausadamente, com a cabeça baixa e respiração pesada, seu desejo por Toni, entre detalhes do encontro real e imagens de sonhos e inseguranças (Fig. 5). Ela narra sua própria história, não adentra a "personagem", recusa-se a atuar e, nisso, consegue 
a atenção do produtor, que as convida para uma festa em sua casa à noite.

Essa cena carrega um comentário sobre a relação que Petzold estabelece entre os seus atores e os dramas que encena. Diante do produtor no casting, uma das garotas tenta convencê-lo ao apresentar uma cena estereotipadamente pautada no envolvimento emocional; porém, não consegue sustentar o personagem. Nina, no entanto, nega a personagem e mostra a si mesma, suas inseguranças, seus gestos contidos, sua fala monocórdica. Seu gestual aproxima-se do que Rosenfeld observa nos atores medievais enquanto postura, na qual predominava uma objetividade religiosa, em que $o$ ator distanciava-se de seus personagens em uma "metamorfose incompleta" (ROSENFELD, 2008, p. 51). Nesse distanciamento, a dicção era monótona, "salmodiante" (obra citada, p. 52), como em uma reza em que não se permitem demonstrações subjetivas de emoção.

A cena do casting de Fantasmas problematiza a velha querela de registros de interpretação polarizados entre a vontade de criar uma mímesis totalizante, focada na comunicação de um sentido textual (o dramático) e outra, oposta, que deixa transparecer o ato de contar sobre o ato de imitar (o épico). Toni tenta se adequar ao estilo dramático dominante: usa de envolvimento emocional face aos seus interlocutores e recebe constante resposta da "plateia" - indo da expressão de enfado das assistentes, o que a deixa ainda mais nervosa, até a intervenção do diretor do casting sugerindo que a música que elas teriam cantado lembraria as de Marlene Dietrich. Nesse jogo, Toni emprega princípios naturalistas, tom de voz variado e em consonância com expressões faciais que dão conta da modulação do texto. Já Nina usa de elementos da retórica épica para interpelar o espectador sem necessariamente envolvê-lo com a trama: voz retraída enunciando momentos murmurados, quase incompreensíveis, rosto sempre voltado para baixo, recurso repetido ao fonema "und" ("e" em português) como embreador discursivo que nos obriga a prestar atenção no significante da linguagem. A resposta da "plateia" à sua frente vai da absorção curiosa até a tomada de posição final do diretor: é por causa da impressão deixada por Nina que ele as convida para a festa. Petzold constrói, assim, uma sequência opaca em que comenta os registros de jogo atoral, posicionando-se abertamente do lado da atuação épica, não naturalista ou brechtiana.

Esses exemplos, em que os gestos expõem os processos sociais e fílmicos por trás deles, subvertem uma lógica da ficção dominante cujas ações escondem o pensamento, a narrativa mascara o discurso, e o produto esconde o processo de fabricação dos filmes e dos jogos atorais. Ao dirigir os atores no 
sentido de terem uma postura autoconsciente em relação ao seu gestual, Petzold permite ao espectador um olhar para a natureza do gesto em si, fazendo com que seu trabalho problematize a ação de construir significado através das escolhas gestuais e posturas corporais.

\section{0 espectador desconfiado}

Ismail Xavier, em uma análise retrospectiva do sistema industrial consolidado, principalmente nos Estados Unidos a partir de 1914, observa que a representação naturalista de Hollywood valeu-se de três elementos básicos para estabelecer a linguagem do cinema como uma "janela" para o mundo. Esses elementos eram: a decupagem clássica "ilusionista"; um método naturalista de atuação, concebida principalmente para filmagens nos cenários dos estúdios; e a escolha de narrativas pertencentes a gêneros narrativos estruturados em convenções de fácil leitura. Em relação ao naturalismo como linguagem desse cinema, Xavier observa:

Tudo neste cinema caminha em direção ao controle total da realidade criada pelas imagens - tudo composto, cronometrado e previsto. Ao mesmo tempo, tudo aponta para a invisibilidade dos meios de produção desta realidade. Em todos os níveis, a palavra de ordem é "parecer verdadeiro"; montar um sistema de representação que procura anular a sua presença como trabalho de representação (XAVIER, 2005, p. 41).
A análise desenvolve-se no sentido dos desdobramentos ideológicos de tal linguagem consolidada pelos estúdios e das manifestações individuais de autores que corroborem ou subvertam a ideologia dominante da indústria. No entanto, para o objetivo deste artigo, é importante deter-se na constatação de como esse meio de representação é fundado. Nos filmes que se enquadram nesta abordagem naturalista e que recorrem aos gêneros cinematográficos como estratégia narrativa, o universo apresentado na trama é dado a ver como uma realidade pronta, sem mediação do dispositivo cinematográfico ou de um produtor do discurso. O espectador do cinema de gênero nos moldes clássicos do naturalismo hollywoodiano deve apresentar uma crença naquilo que lhe é mostrado: a experiência do filme mostrando-se como a percepção de uma realidade pronta. Nisso, a encenação dentro de tais obras neutraliza a presença do realizador na ordenação dos fatos, de modo que todos os elementos escondam o processo por trás deles.

Tendo como base tais elementos básicos enumerados por Xavier para a estruturação da representação naturalista, é possível observar que Petzold subverte essa lógica ao atacar, mais frontalmente, a atuação como elemento de garantia de um naturalismo dominante, ao dirigir seus atores para que, em seu gestual, mostrem-se as nuances sociais dos fatos 
narrados - os outros dois pilares da estética naturalista são, em alguma medida, mais respeitados.

Em outras palavras, Petzold vale-se dos princípios clássicos da decupagem e prefere as convenções dos gêneros cinematográficos para contar histórias, mas cria estranhamento, uma vez que os atores não apresentam uma "metamorfose" completa em personagens, fugindo ao equilíbrio dramático do naturalismo. Nisso, o espectador é colocado diante de narrativas familiares, mas aquilo a que a encenação visa não é garantir a crença desse espectador diante delas e sim desenvolver nele um olhar crítico.

Thomas Schatz identifica um gênero cinematográfico essencialmente como um sistema narrativo, que pode ser analisado através de elementos como trama, personagens, temas, estilos, dentre outros. Segundo ele, através desse sistema, existe um contrato tácito entre o produtor e o público, que os filmes de gênero honram, uma vez que neles se identificam retomadas de certas convenções narrativas e plásticas. Schatz observa que esse sistema do gênero é, ao mesmo tempo, estático e dinâmico, visto que mantém características temáticas e formais estabelecidas para aquele tipo de narrativa, ao mesmo tempo em que sofrem constante variação, influenciados por outros gêneros, pelo contexto social e pela evolução das formas genéricas: é a dialética da continuidade/variação, estruturante para todos os gêneros cinematográficos (sCHATZ, 1981, p. 15-18).

Uma vez estabelecido tal contrato, o espectador passa a confiar que o filme a que irá assistir no cinema relaciona-se com as suas expectativas. Para tal, os responsáveis pela produção do filme concebem o universo daquela narrativa a partir de elementos comuns a outras obras do gênero, apresentando-os através da ideia de naturalidade, que faz com que o público familiarize-se com o que lhe é mostrado, e mantendo a atenção do espectador puramente na experiência do filme, de modo que ele não olhe para fatores externos a ele.

Petzold, no entanto, tem outra postura em relação a esse sistema dos gêneros, identificado por Schatz, adotando a abordagem genérica em um momento em que tais formas narrativas já foram retrabalhadas de inúmeras maneiras: a transparência do período clássico, a reflexividade do período moderno, o maneirismo do contemporâneo. Encarando o lugar de esgotamento das narrativas dramáticas, Petzold assume a postura de fazer filmes "no cemitério do cinema de gênero, a partir dos restos que ainda estão lá, disponíveis" (ABEL, 2013, p. 63). Essa postura de trabalhar a partir de um certo esgotamento 
das formas assemelha-se ao momento maneirista entre meados da década de 1970 e a década de 1980.

Alain Bergala (1985) observa na obra de alguns cineastas uma atitude semelhante à de pintores como Pontormo ou Parmigianino em relação a mestres como Michelangelo ou Rafael. Estes teriam alcançado tamanha perfeição artística a ponto de os artistas que os sucederam terem a sensação de haver chegado tarde demais. Assim, Bergala identifica tal sensação também em cineastas como Wim Wenders, Jim Jarmusch e Lars Von Trier, os quais realizaram filmes após o fim de uma modernidade cinematográfica nos anos 70. Nisso, o maneirismo cinematográfico é uma resposta a uma dificuldade formal e a uma crise dos temas, uma vez que a forma clássica do cinema havia chegado à perfeição, e o cinema moderno havia chegado a um esgotamento.

Luiz Carlos Gonçalves de Oliveira Júnior (2010, p. 73-74) observa diferentes níveis engendrados pelo maneirismo, dentre elas a modificação das formas plásticas pela dilatação ou aceleração das durações. Petzold, inserido no contexto do cinema contemporâneo pós-maneirismo, partilha dessa postura de se ver diante de formas esgotadas pela repetição e por diversas releituras ao longo da história do cinema, de modo que o cineasta traz para tais narrativas de gênero suas próprias "maneiras" de autor. No entanto, enquanto Bergala e Oliveira observam, nos cineastas do período maneirista, o desejo de novas formas em autores solitários embora contemporâneos, é possível compreender a obra de Petzold como um cinema inserido em um contexto em que a rarefação e os registros cênicos mais discretos mostram-se estéticas consolidadas, característica que o cineasta divide com seus colegas da "Escola de Berlim", bem como com outros autores ao redor do mundo (Lucrecia Martel e Claire Denis).

Então, adentrando o cinema de gênero em uma postura de desconstrução, Petzold utiliza-se de suas convenções para narrar não apenas os acontecimentos pelos quais os personagens passam, mas os estados físicos e emocionais que eles carregam em meio a eles, a rarefação dramática sendo intensificada pelo minimalismo do trabalho dos atores. O espectador vê-se, portanto, colocado diante de narrativas que lhe são minimamente familiares pelas convenções de gênero, mas que expõem, através dos gestos dos atores, o caráter de comunicação (ou de dificuldade dela) por trás das relações entre os personagens. A partir disso, tem-se acesso a todo o contexto político em que esses personagens se encontram e o consequente posicionamento questionador sobre seu lugar diante daquela narrativa, uma vez que o filme não é levado para uma 
determinada direção através dos meios convencionais de narrativa e encenação. Diante da desconfiança enquanto estado das coisas, reiteradamente expressa pela mise-en-scène de Petzold, o espectador também desconfia e, assim, sua atitude não é a de tomar as situações representadas como naturais, mas a de tomar consciência dos processos sociais e estruturantes por trás delas.

Bornheim, ao analisar o efeito de distanciamento no que diz respeito ao espectador, lembra seu lugar diante do espetáculo teatral:

Há duas posturas básicas para definir o público. Uma, que torna o público passivo, entregue a um comportamento aparentado ao da hipnose e que manipula os seus sentimentos e as suas ideias [...]. Já a outra postura busca tornar o espectador ativo, fazer com que ele tome consciência da realidade em que vive. Ao menos para o nosso tempo, tal seria a alternativa ineludível: ou bem se transforma o homem em objeto, ou então se procura fazer dele um sujeito (BORNHEIM, 1992, p. 253).

Essa postura ativa do espectador que Bornheim identifica como objetivo do trabalho de Brecht encontra eco na obra de Petzold, que, por sua vez, busca atingi-la através de domínios da representação antes abordados pela via do naturalismo. Ao escolher a abordagem dos gêneros, o realizador alinha-se a um tipo de expressão ligada a matrizes populares, operando, assim, o distanciamento do próprio espectador, que percebe/problematiza o próprio ato de ver, uma vez que é surpreendido pelo ato de mostrar, comumente escondido nesse tipo de narrativa.

\section{Considerações Finais}

Assim, no início do Século xx, com a consolidação da linguagem clássica e naturalista do cinema, estabeleceu-se a padronização estética para a indústria. Cineastas como Sirk e Fassbinder, movidos por uma ideologia oposta ao status quo de sua época, utilizaram o cinema de gênero como uma forma de comentário às diversas estruturas sociais que influíam nas relações entre os indivíduos. Seguindo essa direção política à sua maneira, Petzold faz uso desse tipo de cinema não como uma postura de renová-lo, mas com o desejo de reutilizá-lo para propor um novo olhar para a história e seus sujeitos.

A partir de um gesto desconfiado do ator, é possível estabelecer lampejos de autorreflexividade na narrativa de modo a tornar explícitas as implicações das relações sociais na ordem. Ao receber esse gesto através do filme, o espectador é tomado pela desconfiança diante de uma narrativa que expõe realidades extrafílmicas. É nessa desconfiança, tornada um gestus revelador de estado das coisas dos processos históricos, que se abre a possibilidade de um olhar crítico e reflexivo. 
Petzold coloca-se, assim, como um cineasta atuando na linhagem da reflexividade e da crítica às formas narrativas dominantes instauradas na Hollywood clássica por Sirk e retomadas depois por Fassbinder, o elo alemão que faltava a essa genealogia eminentemente teuto-romântico-desconstrutiva.

\section{Referências}

ABEL, Marco. $O$ cinema de identificação me irrita: entrevista com Christian Petzold. In ZACHARIAS, J. C. Escola de Berlim. 2. Ed. Rio de Janeiro: Stamppa: 2013. p. 56-83

BERGALA, Alain. De uma certa maneira. Abril de 1985. Disponível em: https:// cultureinjection.wordpress.com/2017/11/26/ alain-bergala-de-certa-maneira-abril-de-1985/ Acesso em: 17/01/2018.

BORNHEIM, Gerd A. Brecht: a estética do teatro. 1. Ed. São Paulo, SP: Graal, 1992. BOURGET, Jean-Loup. Le mélodrame hollywoodien. Paris : Stock, 1985.

BRECHT, Bertolt. Estudos sobre teatro. 1. Ed. Rio de Janeiro, RJ: Nova Fronteira, 1978.

COOK, Roger F.; KOPP, K. e PRAGER, B. Introduction: The Berlin School - Under Observation. In COOK, Roger F.; KOEPNICK, L.; KOPP, K. e PRAGER, B. (Eds). Berlin School Glossary. An ABC of the new wave in German Cinema. 1. Ed. Bristol/UK: Intellect, 2013. p. 1-25 FASSBINDER Rainer Werner. Anarquia da Fantasia. 1. Ed. Rio de Janeiro, Zahar, 1988. FISHER, Jaimey. Christian Petzold. 1. Ed. Urbana: University of Illionis Press, 2013.
OLIVEIRA, Luiz Carlos Gonçalves. 0 cinema de fluxo e a mise-en-scène. Biblioteca Digital da Universidade de São Paulo, 2010. Disponível em: http://www.teses.usp.br/teses/ disponiveis/27/27161/tde-30112010-164937/ptbr.php Acesso em: 17/01/2018.

ROSENFELD, Anatol. O Teatro Épico. 6. Ed. São Paulo, SP: Perspectiva, 2008.

\section{SEESSLEN, Georg. Uma escola do olhar: o} projeto aberto dos cineastes da "Escola de Berlim”. In ZACHARIAS, Georg. Escola de Berlim. 2. Ed. Rio de Janeiro: Stamppa: 2013. p. 9-20

SCHATZ, Thomas. Hollywood genres: formulas, filmmaking, and the studio system. 1. Ed. Boston: McGraw-Hill, 1981.

XAVIER, Ismail. 0 discurso cinematográfico: a opacidade e a transparência. 3. Ed. São Paulo, Sp: Paz e Terra, 2005. 


\section{Mistrust as an element of self-reflexivity in Christian Petzold's cinema}

\section{Abstract}

The article investigates how the representation of a sense of distrust as a component of the acting and agency of the elements of mise en scène and film reception is presented as a fundamental element in the work of Christian Petzold. Through the film analysis, different levels will be studied in which this element of film composition is present: in the construction of the visuality and the rhythm of the film through its mise en scène, aiming at a clear political effect in the wake of the epic commentary; in the strategies of self-conscious acting, discussion on acting studies' tradition and the relations between acting in the cinema and theater; and a means by which distancing is created in the viewer, kind of unfolding of previous strategies. Petzold continues the aesthetic proposals of Douglas Sirk and Rainer Werner Fassbinder, using the domain of cinematographic genres as a ground for a political cinema, seeking a staging that exposes the social and historical processes that form the society portrayed in his films.

\section{Keywords}

Film theory and aesthetics. Film genres. Acting studies.

\section{La desconfianza cómo elemento de auto-reflexividad en el cine de Christian Petzold}

\section{Resumen}

El articulo investiga como la desconfianza se presenta como un elemento fundamental en la obra de Christian Petzold, analizando los diferentes niveles en que se hace presente: una condición política que existe en medio de las narrativas; una estrategia para un juego atoral autoconsciente; $y$ un medio que crea distanciamento en el espectador. Petzold da continuidad a las propuestas estéticas de Douglas Sirk e Rainer Werner Fassbinder al utilizar el dominio de los géneros cinematográficos como un terreno para un cine político, buscando una escenificación que expone los procesos históricos y sociales que forman la sociedad retratada en sus películas.

\section{Palabras-clave}

Teoría y estética del cine. Géneros cinematográficos. Estudios actorales.

\section{Pedro Guimarães}

Doutor em Cinema e Audiovisual pela Universidade Sorbonne Nouvelle (Paris III) e Pós-doutor em Cinema no Departamento de Cinema, TV e Rádio da Escola de Comunicações e Artes da Universidade de São Paulo (CTR-ECA/USP). Professor do Departamento de Cinema e do Programa de Pós-Graduação em Multimeios da Universidade Estadual de Campinas - Unicamp, Campinas, São Paulo, Brasil. E-mail: pedromacielguimaraes@gmail.com ORCID: https://orcid.org/0000-0002-5366-1481

\section{David Ken Gomes Terao}

Mestrando da Universidade Estadual de Campinas

- Unicamp, Campinas, São Paulo, Brasil.

E-mail: davidterao@gmail.com

ORCID: https://orcid.org/0000-0002-1636-1658
Concepção e desenho do estudo:

Pedro Guimarães, David Ken Gomes Terao Aquisição, análise ou interpretação dos dados: Pedro Guimarães, David Ken Gomes Terao Redação do manuscrito: Pedro Guimarães, David Ken Gomes Terao Revisão crítica do conteúdo intelectual: Pedro Guimarães 